\title{
Practical considerations when administering surfactants to preterm infants with respiratory distress syndrome
}

\author{
Heui Seung Jo, MD, PhD \\ Department of Pediatrics, CHA University, CHA Bundang Medical Center, Seongnam, Korea
}

Respiratory failure secondary to surfactant deficiency is a major cause of morbidity and mortality in preterm infants. Surfactant replacement therapy (SRT) is essential for preterm infants who have surfactant deficiencies or dysfunction. SRT improves oxygenation and lung compliance, decreases the incidence of air leaks, and thereby makes a decisive contribution to increasing the neonatal survival rate. ${ }^{1)}$

After the successful treatment of respiratory distress syndrome (RDS) with a modified bovine surfactant (Surfactant-TA, Surfacten, Mitsubishi Tanabe Pharma Corp., Tokyo, Japan) by Fujiwara in 1980, various exogenous pulmonary surfactants have been developed and marketed. ${ }^{2)}$ Surfactant-TA was first released in Korea in 1990. Three kinds of animal-derived natural surfactant preparations are currently used in Korea: Poractant alfa (minced porcine lung extract; Curosurf, Chiesi Farmaceutici SpA, Parma, Italy), Calfactant (calf lung lavage extract; Infasurf, ONY, Inc., NY, USA) and a modified bovine lung surfactant produced domestically (Newfactan, Yuhan Corp., Seoul, Korea). ${ }^{3,4}$ Comparisons of efficacy and effects on morbidity revealed no significant differences among these surfactant treatment groups. ${ }^{2-4)}$

In a recent issue of the Korean Journal of Pediatrics, Jeon ${ }^{5}$ reviewed surfactant preparations for preterm infants with RDS. This review article summarizes various randomized controlled trials (RCTs) and meta-analyses among many different synthetic and natural surfactant preparations. In particular, it details information regarding new synthetic surfactants, Lucinactant (synthetic surfactant containing analogues of SP-B; Surfaxin, Discovery Laboratories Inc., Warrington, PA, USA) and CHF 5633 (synthetic surfactant containing analogues of SP-B and $\mathrm{SP}-\mathrm{C}$ ). Lucinactant is currently unavailable because it failed to show a superior effect over natural surfactants, and is inconvenient to use. ${ }^{3)}$ The development of synthetic surfactants has been receiving increasing attention due to concerns over transmitted disease or antigenic complications from animal products. After the first human trial on CHF 5633 in RDS, a larger RCT is currently ongoing in the United States. ${ }^{3)}$ There has also been a study of other specific analogues of SP-B and SP-C in Korea. ${ }^{\text {() }}$

The timing of surfactant administration after birth has shown to be significant. Early SRT (within the first 2 hours after birth) showed more effective results compared to delayed selective surfactant administration. ${ }^{7)}$ Thus far, early rescue SRT has remained the fundamental treatment policy. ${ }^{8)}$ For extremely preterm infants, prophylactic surfactant was recommended to improve their possibility of survival. ${ }^{2,3,8}$ Based on the research results, prophylactic SRT was approved in Korea by the National Health Insurance in 2011 for use in only preterm infants born at $<30$ weeks of gestation or with a birth weight of $\leq 1,250 \mathrm{~g}$. According to the 2017 Korean Neonatal Network Annual Report, 76.0\% out of 2,140 very low birth weight infants were administrated surfactant. ${ }^{9)}$ Among the treated infants, $70.9 \%$ were treated prophylactically.

Recently, popular treatment of antenatal steroids, diverse delivery room stabilization, and improved respiratory support through noninvasive ventilation in the delivery room have
Corresponding author: Heui Seung Jo, MD Department of Pediatrics, CHA University, CHA Bundang Medical Center, 59-Yatap-ro, Bundanggu, Seongnam 13496, Korea

Tel: 82-31-780-5230

Fax: 82-31-780-5239

E-mail: joneona@cha.ac.kr

https://orcid.org/0000-0001-6406-2153

Received: 25 April, 2019

Revised: 22 July, 2019

Accepted: 13 August, 2019

See the article "Surfactant preparations for preterm infants with respiratory distress syndrome: past, present, and future" in Volume 62 on page 155.

Copyright (c) 2019 by The Korean Pediatric Society

This is an open-access article distributed under the terms of the Creative Commons Attribution NonCommercial License (http://creativecommons.org/ licenses/by-nc/4.0/ which permits unrestricted noncommercial use, distribution, and reproduction in any medium, provided the original work is properly cited. 
led to the reassessment of the effectiveness of previous treatment strategies. ${ }^{2,3,10)}$ Early initiation of continuous positive airway pressure (CPAP) following selective SRT is considered an optimal respiratory support for preterm infants with RDS ${ }^{8,10}$ To minimize potential injury by intubation or mechanical ventilation, a number of newer and less invasive methods of surfactant delivery have been studied and recommended, such as brief intubation, thin catheter as an alternative to an endotracheal tube, intrapharyngeal instillation, laryngeal mask administration, and aerosolized surfactant. ${ }^{3,8)}$ The involvement of experienced staff who have successfully performed newer procedures is absolutely necessary.

Immediate intubation and SRT is also important for selective preterm infants with severe RDS. Their maturity and various combined respiratory or systemic diseases are associated with the severity of RDS. For infants with severe RDS or underlying problems requiring continuous ventilator treatment, surfactant administration via a thin catheter is not appropriate. Tailored treatment according to each patient's specific situation and indication is desirable.

In conclusion, we should first decide whether SRT is necessary, and then consider the optimal timing and method of surfactant administration when preterm infants are born; each step should be individualized to each patient's condition. The early use of CPAP with selective surfactant administration and minimal invasive respiratory support is recommended. For infants with severe RDS who do not respond to the usual delivery room stabilization management including noninvasive respiratory care, early intubation and prompt SRT is required.

\section{Conflicts of interest}

No potential conflicts of interest relevant to this article are reported

\section{References}

1. Seger N, Soll R. Animal derived surfactant extract for treatment of respiratory distress syndrome. Cochrane Database Syst Rev 2009; (2):CD007836.

2. Halliday HL. Surfactants: past, present and future. J Perinatol 2008;28 Suppl 1:S47-56.

3. Sardesai S, Biniwale M, Wertheimer F, Garingo A, Ramanathan R. Evolution of surfactant therapy for respiratory distress syndrome: past, present, and future. Pediatr Res 2017;81:240-8.

4. Choi CW, Hwang JH, Yoo EJ, Kim KA, Koh SY, Lee YK, et al. Comparison of clinical efficacy of Newfactan versus Surfacten for the treatment of respiratory distress syndrome in the newborn infants. $\mathrm{J}$ Korean Med Sci 2005;20:591-7.

5. Jeon GW. Surfactant preparations for preterm infants with respiratory distress syndrome: past, present, and future. Korean J Pediatr 2019; 62:155-61.

6. Choi YS, Chung SH, Bae CW. A combination of short and simple surfactant protein $\mathrm{B}$ and $\mathrm{C}$ analogues as a new synthetic surfactant: in vitro and animal experiments. Yonsei Med J 2017;58:823-8.

7. Bahadue FL, Soll R. Early versus delayed selective surfactant treatment for neonatal respiratory distress syndrome. Cochrane Database Syst Rev 2012;11:CD001456.

8. Sweet DG, Carnielli V, Greisen G, Hallman M, Ozek E, Te Pas A, et al. European Consensus Guidelines on the Management of Respiratory Distress Syndrome - 2019 Update. Neonatology 2019;115:432-50.

9. The Executive Committee of Korean Neonatal Network. 2017 Korean Neonatal Network Annual Report. Cheongju (Korea); Korean Centers for Disease Control and Prevention, 2018: 96-100.

10. Committee on Fetus and Newborn; American Academy of Pediatrics. Respiratory support in preterm infants at birth. Pediatrics 2014;133: 171-4. 